\title{
THE IMPORTANCE OF URODYNAMIC EXAMINATIONS IN RELATION TO THE INDICATION FOR SURGICAL TREATMENT OF NEUROGENIC BLADDER DYSFUNCTION
}

\author{
By M. Stoehrer M.D., D. Loechner-Ernst, and B. Mandalka. \\ Urological Department, BG-Unfallklinik, D-8I Io Murnau, Germany.
}

Summary. From 1976 to 1982 more than 5200 urodynamic examinations were performed in our centre. More than 2000 spinal cord injured patients were examined urodynamically one or more times. Modern urodynamics enable an adequate individual surgical treatment in most cases. So it is possible to bring the bladder outlet in an appropriate relationship to detrusors efficiency. Micturition of nearly physiological pressure-flow relation will be achieved without too much of incontinance.

Surgical intervention can be done much earlier and carefully directed. All patients with surgical interventions were controlled urodynamically 6 months later.

Our results and a check-up system with important parameters will be reported.

Key words: Urodynamics; Neurogenic bladder dysfunction; Surgical treatment.

THE DIAGNOSIS of neurogenic bladder dysfunction by urodynamic methods permits a highly selective approach to the therapy for spinal cord injured patients. From January 1976 to the end of April I983, more than 5200 urodynamic examinations have been carried out in more than 2000 spinal cord injured patients. Video micturating cystourethrography with simultaneous recording of bladder pressure, rectal pressure, differential pressure, urinary volume and urinary flow has been used. During the last few years the dynamic urethral pressure profile (Rossier I974; Rossier et al., I980) and the interrupted urethral pressure profiles have been measured. In addition to the video records, the important momentary phases of micturition have been recorded on polaroid films. The pressure flow relation together with radiographic results usually permits sufficient evaluation of the external sphincter so that the more qualitative electromyogram (EMG) is generally omitted.

With experience it may appear possible to forego part of the complex urodynamic diagnostic procedure, but it has been commonly shown that in spite of unchanged clinical findings, considerable changes were found in the urinary tract within 6 months of injury. In most of these patients, bladder emptying required great expenditure of energy but with treatment the prognosis for these patients is favourable (Stoehrer et al., I980; Stoehrer, I98 I). In individual patients irreversible damage has already occurred after one year. It is our goal to obtain well balanced bladder emptying where the bladder outlet is brought into an appropriate physiological relationship to the detrusor's efficiency.

This goal can be reached by both conservative and surgical measures and drug therapy can be used selectively when urodynamic findings are available (Kiesswetter, I979). The considerable side effects associated with the necessary dosage may often prevent effective use of important drugs, and 
in our opinion conservative therapy should therefore be applied only for a limited period of a few months. Surgical therapy may be advanced decisively and the efficiency of specific and individual measures can be tested (Stoehrer, I98I).

The urological department at the 'Berufsgenossenschaftliche Unfallklinik Murnau' was established 7 years ago to care for 80 permanent hospitalised patients with spinal cord injury. Annual urodynamic follow-up examination of all patients have been carried out in order to evaluate therapeutic efficiency. We are chiefly concerned with patients with unbalanced bladders emptying during the first year post-injury, because during this period the future development of the disease is initiated. As we do our urodynamic examinations approximately between the Ioth and I $4^{\text {th }}$ week, enough time remains to operate on sphincter dyssynergia during the primary treatment. The indication for the individual case is determined by the subsequently specified criteria. In case the results do not require operative correction, we control the urodynamic findings after 6 months. As the average duration of the primary hospital stay is 4 to 5 months, there is enough time in every case to check success before release. Seventy per cent of patients have a complete or incomplete upper motor neuron lesion and develop a more or less sufficient reflex bladder. Previously, after initial treatment (Phase I, Table I) such patients are often discharged with adequate reflex bladder activity by triggering and emptying without residual urine but 6-I 2 months later the follow-up study showed morphological changes of the detrusor, compensatory hypertrophy with urethral congestion as well as vesico-ureteral and adnexal reflux (Figs. I, 2). In such patients (Table I), urodynamic findings are characterised by low-compliance and often show detrusor hypercontractility as well as increased reflex behaviour. The capacity is considerably less than $200 \mathrm{ml}$ and the pressure-flow relation is unfavourable. The maximum micturition pressure may be more than $I 20 \mathrm{~cm}$ of water and the maximum flow rate is often only $5 \mathrm{ml} / \mathrm{s}$. There is massive detrusor sphincter dyssynergia with appropriate pressures in the proximal urethra. In these cases the relative indication for surgical reduction of the elevated bladder outlet resistance has been disregarded.

High residual urines are always unfavourable but the absence of a residual urine does not point to efficient bladder emptying. During this early phase persisting or recurrent urinary infection often does not occur. Maximum intravesical pressure during triggering and detrusor tonus during filling are of primary importance. It is important to adjust the maximum average filling rate and to heat the filling fluid to body

TABLE I

Urological treatment of spinal cord injured patients

Phase I: (About 6 months Symptomatic therapy intermittend catheterisation after accident) (Bladder capacity $<400 \mathrm{ml}$ ) bladder training (Hospitalized) clarification-motivation

Phase II: (Until the end of Achievement of well compensated micturition second year)

Phase III: (Follow up) Sustaining the results of urological treatment (yearly check-up). 


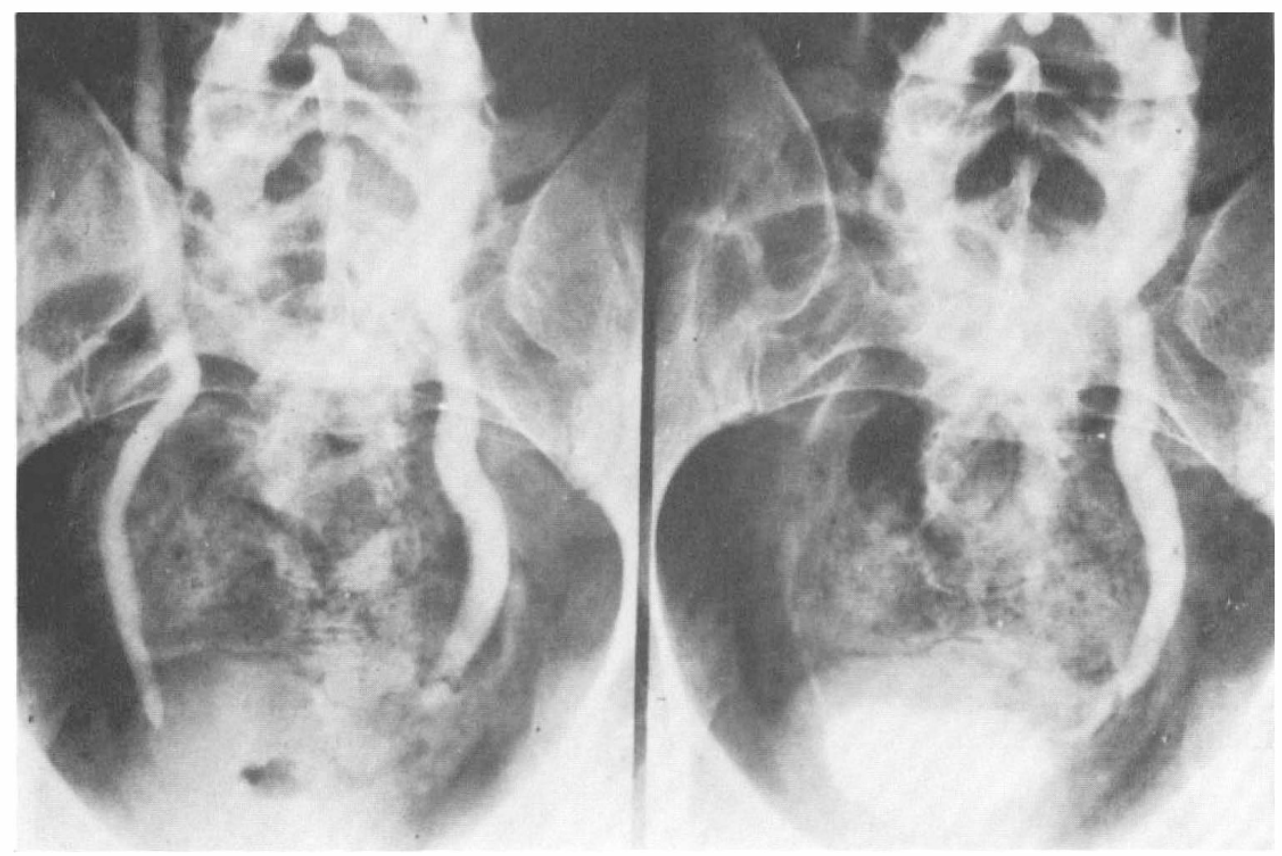

FIG. I

Prevesical congestion after compensatory detrusor-hypertrophy in case of detrusorsphincter-dyssynergy.
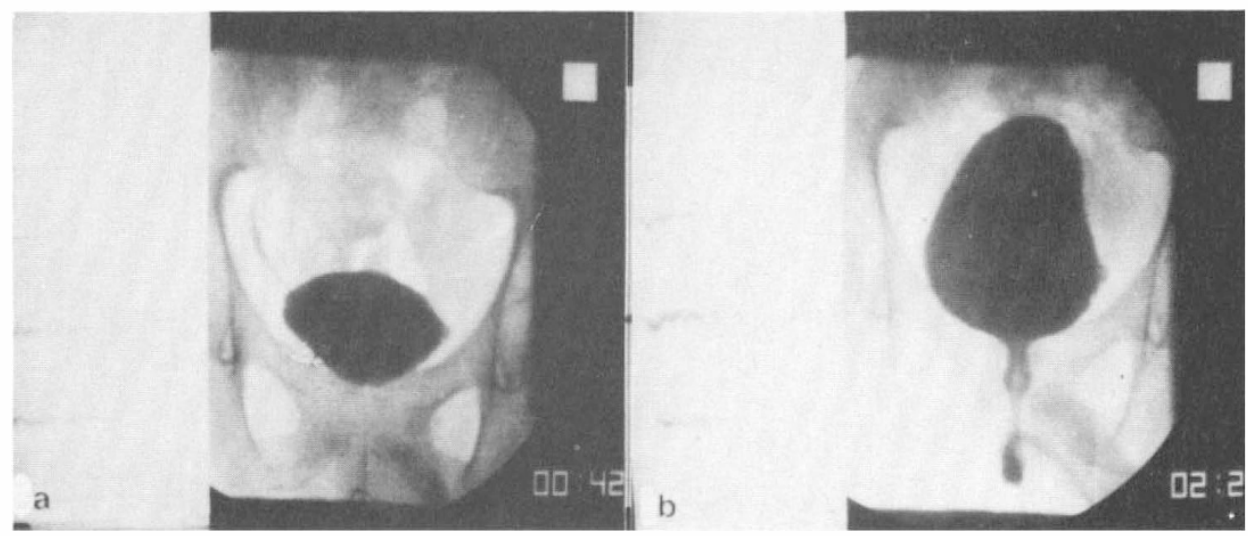

FIG. 2

Hypercontractile detrusor 6-month after spinal cord injury. (a) Low-pressure reflux in the filling phase. (b) No reflux during micturition.

temperature. The bladder response to triggering may also become aggressive. In general we believe that patients with sufficient bladder capacity (more than $250 \mathrm{ml}$ ) who empty reflexly without triggering up to pressures of 50 to $100 \mathrm{~cm}$ of water, should omit triggering. 
TABLE II

Indication for external sphincter incision

Detrusor Sphincter Dyssynergia

High bladder pressure $\left(>\mathrm{I} 00 \mathrm{~cm} \mathrm{H}_{2} \mathrm{O}\right.$ )

+ Hypertonus of detrusor (Compliance $<20 \mathrm{ml} / \mathrm{cm} \mathrm{H}_{2} \mathrm{O}$ )

+ Small capacity $(<200 \mathrm{ml})$

A reduction in compliance always represents insufficient detrusor adaptation to filling and shows a tendency towards an overactive, even aggressive, detrusor contraction. An infusion urogram often additionally shows an adnexal reflux or prevesical dilatation owing to increased pressure on the intramural part of the ureter.

Low compliance with maximum bladder pressure exceeding $100 \mathrm{~cm}$ of water during micturition and fast detrusor contractility during triggering are decisive factors for early indication of sphincterotomy (Table II, Figs. 3a \& b). Sphincterotomy is carried out on the basis of a considerably shortened incomplete modification of the method described by Madersbacher and Scott

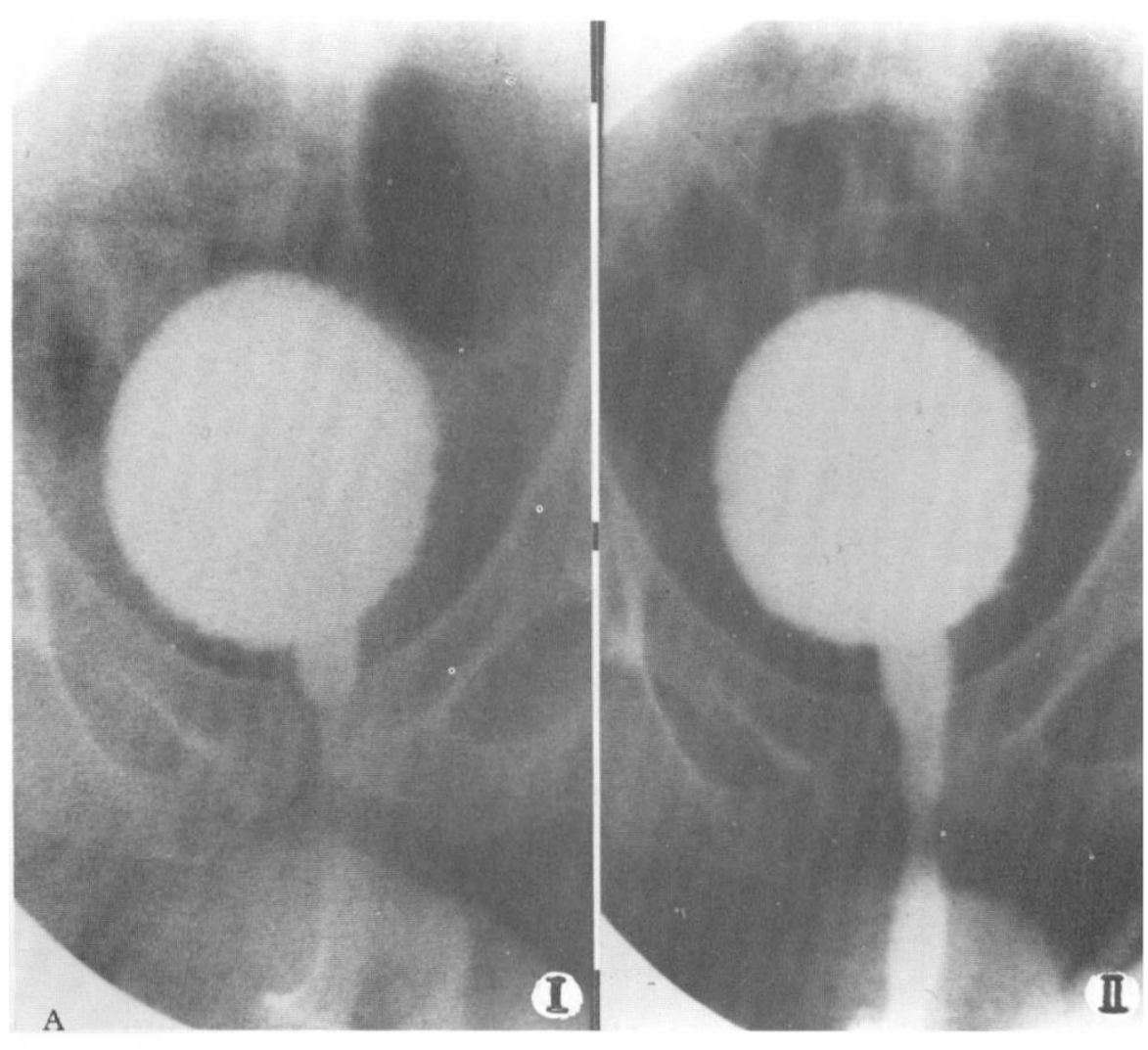

FIG. 3A 


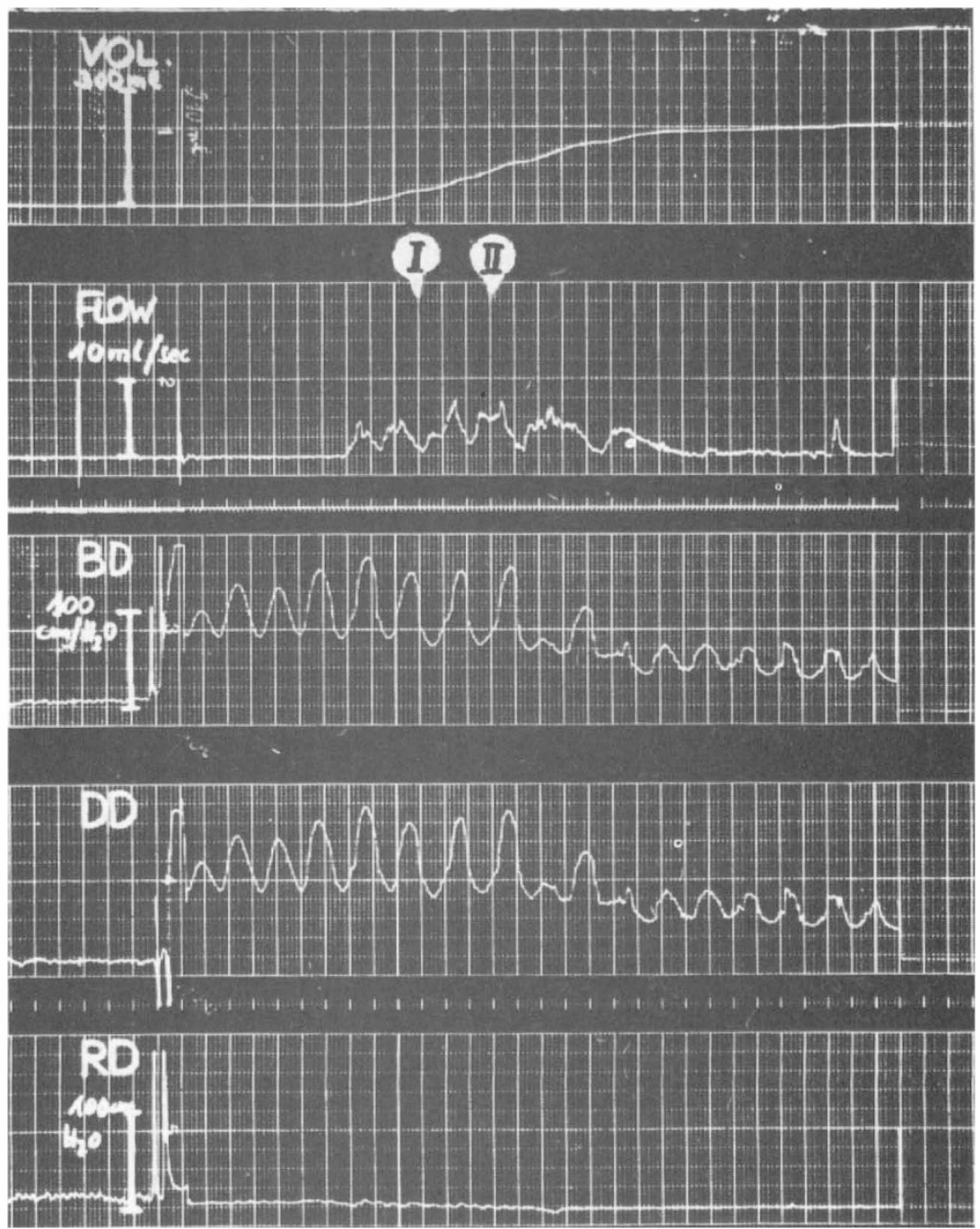

Fig. 3B

Early indication for incomplete sphincter externus incision in detrusor-sphincterdyssynergia. (A) videotape. (B) $\mathrm{BD}=$ bladder pressure, $\mathrm{DD}=$ differential pressure, $\mathrm{RD}=$ rectal pressure.

(I976) using the electric knife at I2 o'clock. The incision only reaches the maximum contractile part and smoothly ends in the lumen of the urethra. The result is controlled urodynamically 6 months post-operatively (Stoehrer, I98I) (Fig. 4). After incomplete sphincter incision maximum bladder pressure normally decreases to values of 50 to $100 \mathrm{~cm}$ of water and the urethral pressure in the region of the external sphincter (SE), also declines considerably. After interrupting detrusor sphincter dyssynergia, the bladder capacity is enlarged due to detrusor relaxation. In addition flow conditions of the upper urinary tract and continence are improved. 


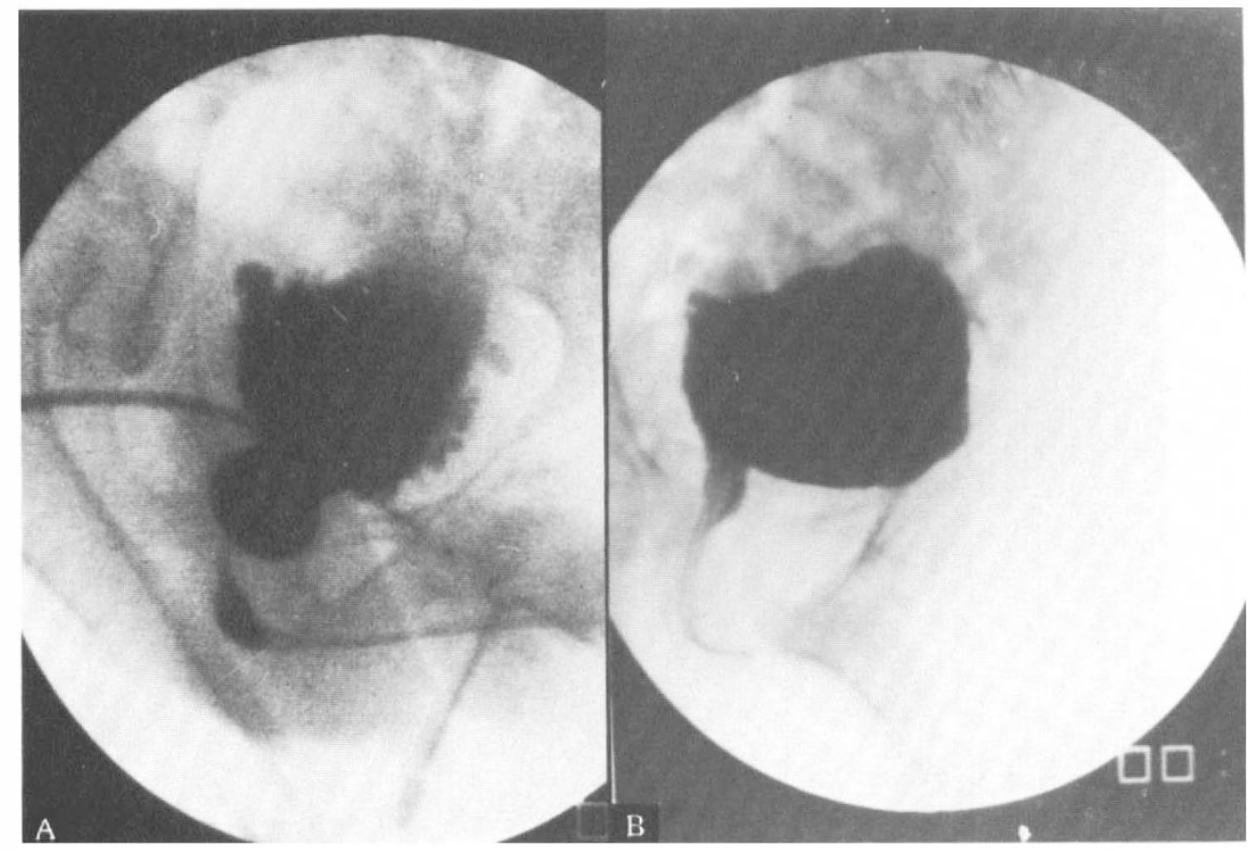

FIG. 4

Reflex-bladder with detrusor sphincter-dyssynergy. (A) I 5 months after injury. (B) I year after incomplete sphincterotomy.

TABLE III

Results of external sphincter incision

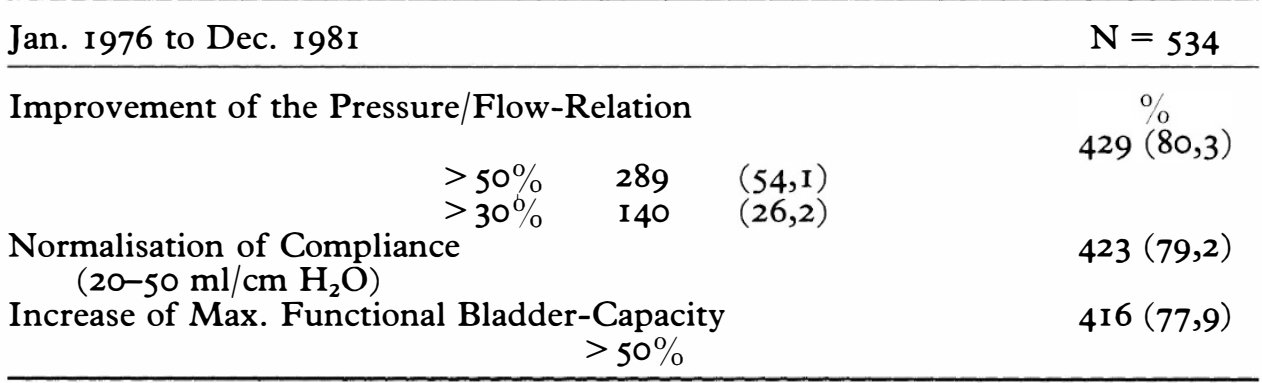

Continence will not be impaired unless all muscle groups of the proximal urethra are excised. This is avoided by the partial sphincterotomy.

From January 1976 to December I982, 534 patients were treated by this surgical method with satisfactory urodynamic results (Table III). Female patients with detrusor sphincter dyssynergia theoretically can be treated according to this method but since these patients cannot use external collecting devices, this is rarely used. However, we have used our modified sphincterotomy on $\mathrm{I} 3$ female patients. The majority suffered from 
permanent incontinence so that surgical intervention could not aggravate the situation. Most of them emptied sufficiently post-operatively but determination of incision length is vital in female patients. Compared to male patients the consequences are serious if the appropriate incision length exceeds only a few millimetres. For this reason we endeavour to use drug therapy and if necessary the female patient is taught to perform selfintermittent catheterisation. We have not tried other operative techniques, such as Otis-urethrotomy to reduce the resistance of bladder-outlet in the female. However, we have noticed, that females were stress incontinent when they were first operated at the bladder-neck without result and then additionally in the external sphincter.

For us the dilation of the female urethra does not seem the appropriate measure to essentially improve the bladder-out-let situation. Every dilation leads to rupturing of fibromusculary tissue, to microscopic bleedings, inflammation and scar formation. To us a secondary scar induced stricture and thus a urinary outflow resistance with loss of elasticity of the urethra does not appear to be a consequent solution of this problem.

The so-called flaccid bladders are managed in a similar manner. The treatment of the so called 'Flaccid Bladder' depends on the condition of the posterior urethra and the muscles of the pelvic floor. With regard to closure area of posterior urethra one could classify functionally in well coordinated sphincterfunction, unrelaxed striated sphincter, denervation of striated sphincter and unrelaxed smooth sphincter. Decisive factors are the required pressure in relation to flow during bladder emptying and the residual urine. It is undesirable in the long term to squeeze the bladder with pressures of 100 to $200 \mathrm{~cm}$ of water. First we support harmonious emptying with drug relaxation of the posterior urethra. If this is not adequate, we incise the bladder neck, if it is passively closed. (Turner Warwick et al., I973). Any scar induced strictures are additionally resected. Resection of the prostate gland may be necessary in case of hypertrophy and mobilisation of the gland following incision into the bladder neck.

The basic problem in therapy of flaccid and hypocontractile bladders lies in the fact that the bladder outlet resistance has to be reduced below that of any detrusor contractility. This always increases the risk of stress incontinence. The patient must be prepared to accept external condom drainage. As an alternative, the patient may perform self-intermittent catheterisation. Later in the treatment of spinal cord injury patients when bladder emptying is stabilised, the above-mentioned surgical approaches are almost sufficient. The indications for extent of surgical intervention depend on the degree of urinary tract injury, but even with massive impairment of renal function, satisfactory results have been achieved. In our population we have not seen any indication for supravesical ureterostomy during the last 7 years and we attribute this to the opportunity of using modern urodynamics.

In the third phase of follow-up treatment, patients have an annual urodynamic assessment. We direct particular attention to the following clinical and urodynamic parameters which we assume appropriate for the evaluation of bladder emptying:

I. Rate of urinary tract infection per year.

2. Signs of congestion in the upper urinary tract. 
3. Reflux. rate.

4. Relation between maximal bladder pressure and maximal flow

5. Relation between maximal bladder capacity and residual urine.

Vesico-ureteric reflux may regress with improved bladder emptying and there is rarely an indication for re-implantation. In the past 7 years this has only been used in three patients out of our total case material. The indication for ureteric re-implantation should be based on the following prerequisites:

I. Maximal bladder pressure does not exceed $50 \mathrm{~cm}$ of water.

2. No gross morphologic changes of the bladder are present.

3. There should be no subvesical obstruction.

The indication for implantation of artificial sphincters is expected to be analogous and we regard a reflex bladder as being an additional contraindication.

\section{Conclusion}

Modern urodynamics permit an accurate and early diagnosis of the neuropathic bladder. This is mandatory for appropriate treatment and the success of bladder management has been significantly proved. In view of these opportunities for assessment and treatment, damage to the urinary tract in spinal cord injured patients is expected to be considerably reduced in the future.

\section{RÉSUMÉ}

De 1976 à 1982 plus de 5200 examens urodynamiques ont été faits dans notre centre. Plus de 2000 paraplégiques ont subi un examen urodynamique une ou plusieurs fois.

L'urodynamique moderne permet dans la plupart des cas un traitement opératif individuel approprié, si bien qu'il est possible d'etablir une relation appropriée entre la resistance du sphincter strié ou le col de la vessie et l'effectivité du detruseur. On peut arriver à une miction avec une relation pression/flux presque physiologique sans devoir prendre en compte une détérioration essentielle de la continence.

L'intervention chirurgicale peut avoir lieu beaucoup plus tôt et de la facon plus méticuleuse.

Tous les patients opérés ont subi un contrôle urodynamique 6 mois plus tard. On communique les résultats et le système de check-up avec des parametres essentiels.

\section{ZUSAMMENFASSUNG}

Von 1976 bis 1982 wurden mehr als 5200 urodynamische Untersuchungen in unserem Zentrum durchgeführt. Über 2000 Querschnittgelähmte wurden urodynamisch ein oder mehrmals untersucht. Die moderne Urodynamik ermöglicht in den meisten Fällen, eine adaequate individuelle operative Behandlung, so daß es möglich ist, den Blasenauslaßwiderstand in eine angemessene Relation zur Detrusorleistung zu bringen. Damit kann eine Miktion mit nahezu physiologischer Druckflußrelation erreicht werden ohne eine wesentliche Verschlechterung der Kontinenz in Kauf nehmen zu müssen.

Die operative Behandlung kann wesentlich frühzeitiger und sorgfältiger erfolgen.

Alle operierten Patienten wurden 6 Monate später urodynamisch kontrolliert. Über die Resultate und über ein Check-up-System mit wesentlichen Parametern wird berichtet. 


\section{REFERENCES}

KIESSWETtER, H. (I979). Medikamentöse Behandlung von neurogenen Blasenentleerungsstörungen. In: Stöhrer, M. (Hrsg) Urologie bei Rückenmarkverletzten, Springer-Verlag Berlin-Heidelberg-New York, 54-69.

MADERSBACHER, H. \& SCOTT, F. B. (I976). The twelve o'clock sphincterotomy: technique, indications, results. Paraplegia, 14, 26I-267.

Rossier, A. B., Fam, B. A., DiBenedetto, M. \& Sarkarati, M. (I980). Urethro-Vesical Function during Spinal Shock. Urological Research, 8, 53-65.

Rossier, A. B. (I 974). Neurogenic Bladder in Spinal Cord Injury. Urologic Clinics of North America-Vol. I, No. I.

STÖHRER, M. (I98I). Die operative Behandlung der Blasenentleerungsstörung beim Querschnittgelähmten. Urologe $A, \mathbf{2 0}, 78-84$, Springer-Verlag Berlin-Heidelberg-New York.

Stöhrer, M., MÜller, A., FARnUng, F., SchöFfner, W. (I980). Urologische Diagnostik und Therapie bei der Behandlung Rückenmarkverletzter. Verhandlungsbericht $d$. Deutschen Gesellschaft für Urologie, 31. Tagung, 284-285, Springer-Verlag, BerlinHeidelberg-New York.

Turner-Warwick, R., Whiteside, C. G., Worth, P. H. L., Milroy, E. J. G. \& Bates, C. P. (I973). Urodynamic View of the Clinical Problems associated with Bladder Neck Dysfunction and its Treatment by Endoscopic Incision and Trans-trigonal Posterior Prostatectomy. British fournal of Urology, 45, 44-59. 